\title{
On Brünnow's Method of correcting the Orbit of a Comet.
}

In the method of varying distances for the correction of a comets orbit occur de following formulae

$$
\triangle \cos \beta \cos \left(\boldsymbol{\lambda}-\boldsymbol{G}^{\prime}\right)+\eta=\boldsymbol{h}^{\prime} \cos \zeta^{\prime} \cos \left(\boldsymbol{H}^{\prime}-\boldsymbol{G}\right)=x^{\prime}
$$

(a) $\triangle \cos \beta \sin (\lambda-G)=h^{\prime} \cos \zeta^{\prime} \sin \left(H^{\prime}-G\right)=y^{\prime}$

$\triangle \sin \beta$

$=h^{\prime} \sin \zeta^{\prime}$

$=\boldsymbol{z}^{\prime}$

where $x^{\prime}, y^{\prime}, z^{\prime}$, are the coordinates of the first place of the comet referred to the last place of the earth.

If the first equation be multiplied by $\cos (\lambda-G)$ and the second by $\sin (\lambda-G)$, adding and transposing, we hawe

$\Delta \cos \beta=\boldsymbol{h}^{\prime} \cos \zeta^{\prime} \cos \left(\lambda-\boldsymbol{H}^{\prime}\right)-\boldsymbol{g} \cos \left(\lambda-\boldsymbol{G}^{\prime}\right)$

Dividing be the last of equations (a)

$$
\cot \beta=\cot \zeta^{\prime} \cos \left(\lambda-H^{\prime}\right)-\frac{g \cos (\lambda-G)}{h \sin \zeta^{\prime}}
$$

which will be found a very convenient check.

To illustrate let $\log \Delta=0.212800$, log $g=$ $0.083425, \beta=46^{\circ} 18^{\circ} 40^{\prime \prime} .7, \lambda=93^{\prime \prime} 6^{\prime} 10^{\prime \prime} .6$ and $\boldsymbol{G}=157^{\prime \prime} 39^{\prime} 3^{\prime \prime} .3$. The computation will be as follows :

$$
\begin{aligned}
& \sin \beta \quad 9.859200 \\
& \triangle 0.212800 \\
& \cos \beta \quad 9.839314 \\
& \sin (\lambda-(x) \quad 9.955662 \\
& \triangle \cos \beta \quad 0.052114 \\
& \cos (\lambda-G) \quad 9.633221 \\
& \text { \% } 0.083425 \\
& 0.146085 \\
& \triangle \cos \beta \cos (\lambda-6) \quad 9.685335 \\
& h^{\prime} \cos \zeta^{\prime} \cos \left(\boldsymbol{H}^{\prime}-\boldsymbol{G}\right) \quad 0.229510 \\
& \text { cos, sin } 9.933200 \\
& \text { h' } \cos \zeta^{\prime} \sin \left(\boldsymbol{H}^{\prime}-G\right) 0.007776
\end{aligned}
$$

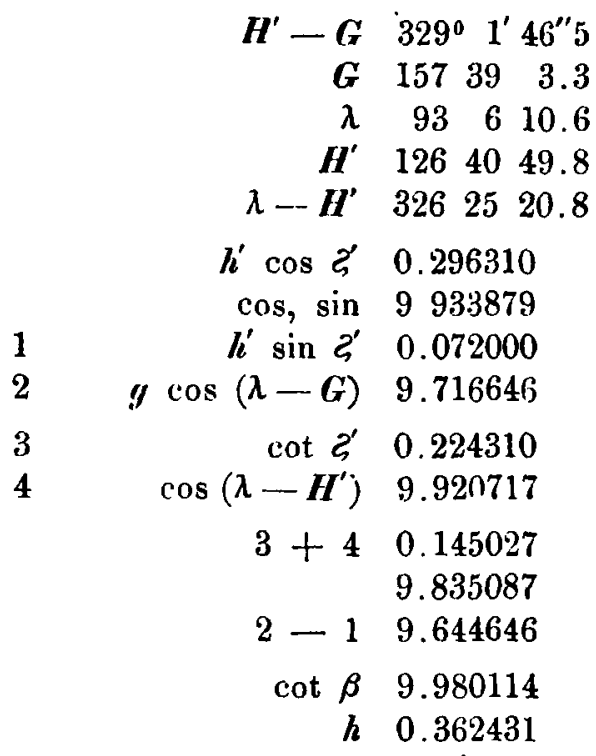

It wil be seen that $\cos \left(\boldsymbol{\lambda}-\boldsymbol{H}^{\prime}\right)$ is the only trigonometric function required for the check which is not already given.

For finding $\varphi^{\prime}$ (i. e. the angle at the last place of the earth between the actual first and last places of the comet) the following are preferable to the ordinary formulae on account of their perfect certainty

$$
\begin{aligned}
m \sin M & =h^{\prime} \cos \zeta^{\prime} \cos \left(\lambda^{\prime \prime}-\boldsymbol{H}\right) \\
m \cos M & =h^{\prime} \sin \zeta^{\prime} \\
h^{\prime} \sin \varphi^{\prime} \cos N & =m \cos \left(M+\beta^{\prime \prime}\right) \\
h^{\prime} \sin \phi^{\prime} \sin N & =h^{\prime} \cos \zeta^{\prime} \sin \left(\lambda^{\prime \prime}-\boldsymbol{H}\right) \\
h^{\prime} \cos \varphi^{\prime} & =m \sin \left(M+\beta^{\prime \prime}\right)
\end{aligned}
$$

$\varphi^{\prime}$ and $N$ need not actually be written down. The work is checked if $l^{\prime}=h^{\prime}$ found from $l^{\prime} \cos \zeta^{\prime}, h^{\prime} \sin \zeta^{\prime}$. .

August 14, 1874.
Ormond Stome.

\section{Verkäufliches Instrument.}

We are going to sell a transit made by Trougliton $\mathcal{S}^{\star}$ Simms 1831, mounted on stone, who has a very fine level and an object glass of $5^{\prime \prime} .2$ clear aperture and a focal lensht of 5 , to the extremely cheap price of Pfi. Sterl. 50. For furthe i structions apply to Dr. Doberck, Markree-Observatory, Collooney, Ireland.

In halt:

Zu No. 2007-2009. V. Knorre. Beobachtungen am grossen Meridiankreise der Berliner Sternwarte. 227. - F. Tieijen. Bcobachtungen ant grossen Meridiankreise der Berliner Sternwarte. 243. - Elomente und Ephemeride des von J. Coggia in Marseille an 19. Angust entdeckten Cométen, herechnet von Ir. J. Holetschek. 261. - C. Feamley. Meridianbeobachilungen des Cometen Coggin. 263. - d'Arrest. Auffindung neuer ausgezeichneter Sternspectra vom III und IV Setrhi'schen Typus No. 1. 263. Ormond Slone. On certain Expressions for the Distance of a Conet from the Earth. 267. - J. Holetsehek. Fortselzung der Ephemeride des von Borrelly an 25. Juli entdeckten Cometen. 269. - J. Holetschek. Elemente und Ephemeride des yon Coggia am 19. August cntdeckten Cumeten. 269. - Ormand. Stone. On Briinnow's Mlelhod of correcting the Orhit of a Conet. 271. Verkäufliches Instrument. 271.

Kiel 1874. Septeuber 28.

Drack von Hencke \& Schachel in Kiel. 